\title{
Elektronik Burun Kullanılarak Arabika (Coffea arabica) ve Robusta (Coffea canephora) Kahvelerinin Ayrıştırılması
}

\begin{abstract}
Ali Can İncegül ${ }^{*}{ }^{*}$, Kubilay Taşdelen ${ }^{2}$
Özet: Elektronik burun (e-burun), kahve, şarap ve bira gibi içeceklerin değerlendirmesinde kullanılan düşük maliyetli, koku üzerine yoğunlaşan bir cihazdır. Kahve, farklı kavurma derecelerinde instant veya içmeye hazır formda bulunan insanlık tarihinin en popüler içeceklerinden birisidir. Bu çalışmada geniş tüketim a ğı bulunan Arabika ve Robusta türü kahvelerin tasarlanan elektronik burun cihazı ile ayrımlarının yapıılması amaçlanmıştır. Bu a maç doğrultusunda MQ (MQ135, MQ2, MQ3, MQ5, MQ6, MQ7 ve MQ8) sensörleri kullanılarak bir elektronik burun düzeneği tasarlanmıştır ve kahve analizleri gerçekleştirilmiştir. Numunelerden alınan sinyaller arduino kartla işlenip MATLAB programına aktarılmıştır. Tasarlanan e-burun cihazının kahveleri ayırıp ayıramadığı ise sınıflandırma a lgoritmaları kullanılarak belirlenmiştir. Cihazdan alınan sinyal değerleri doğrusal ayırma ana lizi (LDA), Bayes, en yakın komşu (kNN-3, kNN-5, kNN-7 ve kNN-9), karar ağac1, oneR ve destek vektör analizi (SVM) algoritmaları kullanılarak sınıflandırılmıștır. Arabika ve Robusta ikili ayrımında en iyi sınıflandırma cevabı MQ7 sensöründen, karar ağacı algoritma analizi ile elde edilmiştir. MQ135 \% 79.63 oranında ayrım yaparken, MQ2, \% 78.46 ve MQ $7 \% 80.92$ oranında ayrım yapabildiği sonucuna varılmıştır. Elde edilen sinyallerin yorumlanmasında yürütülen sınıflandırma çalışmaları sonucunda en iyi sınıflandırmalar karar ağaçlarından (decision trees) elde edilmiştir ve diğer sınıflandırma yöntemlerine göre daha yüksek başarı sa ğla dığı görülmüştür. Yürütülen bu çalışma ile kahve sektörü için önemli bir sorun olan daha ucuz kahvelerin ka liteli olanlar ile karıștırılması durumu hızlı ve ekonomik bir şekilde dizayn edilen e-burun düzeneği sayesinde tespit edilmiştir.
\end{abstract}

Anahtar kelime: Elektronik burun, kahve, sensör, sınıflandırma, MQ, a rabika.

\section{Separating Arabica (Coffea arabica) and Robusta (Coffea canephora) Coffees Using Electronic Nose}

\begin{abstract}
The electronic nose (e-nose) is a low-cost device that focuses on fragrance used in the evaluation of beverages such as coffee, wine and beer. Coffee is one of the most popularbeverages in human history, available in instant or ready-to-drink form at different roasting degrees. In this study, it is aimed to distinguish the coffees of Arabica and Robusta types, which have a wide consumption network, with the designed electronic nose device. For this purpose, an electronic nose assembly was designed using MQ (MQ135, MQ2, MQ3, MQ5, MQ6, MQ7 and MQ8) sensors and coffee analyzes were performed. The signals taken from the samples were processed with the arduino card and transferred to the MATLAB program. Whether the designed e-nose device could separate the coffees was determined using classification algorithms. The signal values received from the device were classified using linear separation analysis (LDA), Bayes, nearest neighbor ( $\mathrm{kNN}-3, \mathrm{kNN}-5, \mathrm{kNN}-7$ and $\mathrm{kNN}-9)$, decision tree, oneR and support vector analysis (SVM) algorithms. The best classification response in the Arabica and Robusta bin ary distinction was obtained from the MQ7 sensor by decision tree algorithm analysis. It was concluded that MQ135 could distinguish 79.63\%, while MQ2, 78.46\% and MQ 7 could distinguish $80.92 \%$. As a result of the classification studies carried out in the in terpretation of the obtained signals, the best classifications were obtained from decision trees and it was observed that they had higher success than other classification methods. With this study, mixing of cheaper coffees with quality ones, which is an important problem for the coffee industry, was determined thanks to the e-nose mechanism designed in a fast and economical way.
\end{abstract}

Keywords: Electronic nose, coffee, sensor, classification, MQ, a rabica 
${ }^{1}$ Address: Isparta Uygulamalı Bilimler Üniversitesi Lisansüstü Eğitim Enstitüsü, 32260, Isparta.

2Address: Isparta Uygulamalı Bilimler Üniversitesi, Teknoloji Fakültesi, Elektrik-Elektronik Mühendisliği, Isparta.

*Corresponding author (sorumlu yazar): alicanincegul@hotmail.com

Citation (atıf): İncegül, A. C., Taşdelen, K. (2021) Elektronik Burun Kullanılarak Arabika (Coffea arabica) ve Robusta (Coffea canephora) Kahvelerinin Ayrıştırılması Bilge International Journal of Science and Technology Research, 5(2):101-106.

\section{GíRiş}

Kokuyu ölçme fikri Alexander Graham Bell tarafından 1914 yılında öne sürülmüş ve elektronik olarak kokuyla ilgili çalışmalar 1961 yılında başlamıştır. İlk elektronik burun tasarımı ise 1964 'te Wilkens, Hatman (Wilkens ve Hartman, 1964) ve Buck tarafından gerçekleştirilmiştir (Chiu ve Tang, 2013). Memelilerin koku alma sistemleri taklit edilerek hazırlanan elektronik burunlar çok sayıda farklı kokuyu ayırabilecek kabiliyete sahiptir. Tasarlanan elektronik burun mekanizmalarında kokuyu yanikim y a sa 1 bileşenleri algılayan bir tanıma sistemi mevcuttur. Bu görevi gaz algilayıcılar olarak nitelendirilen sensörler gerçekleştirmektedir. Koku bilgisi olarak algılanan sinyaller elektronik bir devre yardımı ile elektrik bilgisine dönüştürülerek yorumlanır. Farklı kullanım alanları için kullanılmak üzere metal oksit yarı iletken sensörler (MOS), katalitik yanma gaz sensörleri, elektrokimyasal gaz sensörleri ve termal iletkenlik gaz sensörleri üretilmiştir (Dey, 2018). Metal oksit yarı iletken sensörleri son teknoloji ile geliştirilen elektronik cihazlar ile uyumluluğu, maliyetinin düşük oluşu ve hassasiyetinin yüksek olması dolayısıyla daha çok tercih edilir hale gelmiştir (Eranna et al., 2004).

Rubiaceae familyasının coffea cinsine mensup olan kahve yapraklarını dökmeyen, ekvatora yakın bölgelerde yetişen ve yağışı seven bir bitki türüdür. Çiğ kahve kültürü yapılan ağaçların meyveleri iken ögütülmüş form, çiğ kahvenin farklı kavurma derecelerinde 1 sıl işleme tabi tutulması sonucu arzu edilen aroma ve iriliğe göre toz forma dönüştürülen kahve şeklinde tanımlanmaktadır (Taştan, 2009). Kahve dünya genelinde severek tüketilen içeceklerin başında gelmektedir. Türkiye iklimi ve konumu kahve yetiştirilmesine uygun olmamasına rağmen kahve Türk kültürünü yakından etkilemiştir. Dünya genelinde 80 tür mevcut iken, ticari olarak değerli olan iki tür, Coffee arabica ve Coffee robusta'd1r. Coffee arabica \% 80-90 dolaylarında üretilirken, Coffee robusta \% 8-9 civarlarında üretilmektedir. Arabika türü Robustaya göre hastalıklara ve parazitlere dayanıksız olduğu için yetiştirilmesi daha zordur. Kimyasal bileşim açısından değerlendirildiğinde ise Robusta türünün Arabikaya göre 2 kat daha fazla kafein içerdiği ve asitliğinin daha düşük olduğu görülmektedir.(M. N. Willson, 1985). Arabika yumuşak içimli bir kahvedir. Kahve Arabika diğer türlere göre daha maliyetli bir tür olduğu için daha ucuz kahveler ile karıştırılarak maliyeti düşürülmeye çalışılmaktadır. Genellikle Robusta türü karıştırılarak hile yapılmaktadır.

$\mathrm{Bu}$ çalışmada da tasarlanan elektronik burun düzeneğinin kahveleri ayırt edip edemeyeceği irdelenmiştir. Bu çalışmanın amacı, ka lay oksit yarı iletken gaz sensörü ola n
MQ sensör dizisi kullanılarak \%100 Arabika ve \%100 Robusta kahve türlerinin analiz edilmesi, elde edilen verilerin farklı sınıflandırma algoritmalan ile yorumlanması ve elektronik burunun ayrim yapma durumunun araştırılma sıdır.

\section{MATERYAL VE YÖNTEM}

Sensörler içerisinde iletken madde bulundurarak koku moleküllerindeki kimyasal bileşenlerle etkileşime girerek iletkenlik değişimi meydana getirmektedirler. Diğer sensör gruplarına göre daha ucuz olan metal oksit yarı iletken gaz sensörleri yüksek hassasiyete sahipliği ve modern elektronik cihazlarla uyumlu oluşu dolayısıyla daha fazla tercih edilmektedir. Bu çalışmada, resöptör ve dönüştürücü olmak üzere iki birimden oluşan metaloksit yarı iletken gaz sensörleri kullanılmıştır. Kullanılan MQ sensörler ve özellikleri Tablo 1'de verilmiştir.

Tablo 1. Ça lışmada kullanılan MQ sensör özellikleri

\begin{tabular}{|c|c|c|}
\hline Sensör & $\begin{array}{l}\text { Hedef } \\
\text { bileșen }\end{array}$ & $\begin{array}{l}\text { Ölçüm } \\
\text { ara lığ1 }\end{array}$ \\
\hline MQ 2 & Metan-Bütan & $\begin{array}{l}\text { 300-10000 } \\
\text { ppm }\end{array}$ \\
\hline MQ 3 & Alkol & $\begin{array}{l}0.04 \mathrm{mg} / \mathrm{L}-4 \\
\mathrm{mg} / \mathrm{L}\end{array}$ \\
\hline MQ 5 & $\begin{array}{l}\text { Bütan- } \\
\text { Propan }\end{array}$ & $\begin{array}{l}\text { 300-10000 } \\
\text { ppm }\end{array}$ \\
\hline MQ 6 & $\begin{array}{l}\text { LPG, } \\
\text { izobütan- } \\
\text { Propan }\end{array}$ & $\begin{array}{l}300-10000 \\
\text { ppm }\end{array}$ \\
\hline MQ 7 & $\begin{array}{l}\text { Karbon } \\
\text { monoksit }\end{array}$ & $\begin{array}{l}10-10000 \\
\text { ppm }\end{array}$ \\
\hline MQ 8 & $\begin{array}{l}\text { Hidrojen, } \\
\text { alkol buharı, } \\
\text { LPG }\end{array}$ & $\begin{array}{l}100-10000 \\
\text { ppm }\end{array}$ \\
\hline MQ 135 & $\begin{array}{l}\text { NH3, NOx, } \\
\text { alkol buhar1, } \\
\text { benzen, } \\
\text { duman ve } \\
\mathrm{CO}_{2}\end{array}$ & $10-300 \mathrm{ppm}$ \\
\hline DHT11 & S1caklik-nem & $\begin{array}{l}\text { S1caklik:- } \\
20-60{ }^{\circ} \mathrm{C} \\
\text { Nem: \% 5- } \\
95\end{array}$ \\
\hline
\end{tabular}

Kullanılan MQ sensörler board üzerine sabitlenerek, çıkış kısımları arduinoya ba ğlanmıştır. Sensörlerin ihtiyacı olan enerji $5 \mathrm{~V}$ harici adaptör aracılığı ile temin edilmiştir. Tasarlanan hazne farklı kokulara duyarlı olacağı için çevreden kaynaklı hataları engellemek için kapalı ve 
sızdırmaz bir örnek ölçüm kabı dizayn edilmiștir. Elektronik burun görüntüsü Şekil 1'de görüldüğü gibidir.

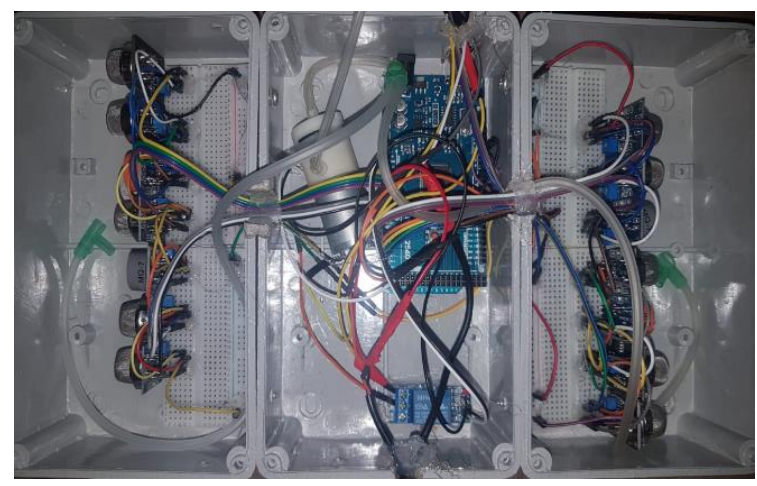

Şekil 1. Ça lışma da ta sarlanan elektronik burun düzeneği

Tasarlanan elektronik burun sisteminden alınan sinyaller bilgisayar ortamına aktarılarak MATLAB programında işlenmiş ve ilgili grafikler elde edilmiştir. Elde edilen veriler daha anlamlı hale getirilmesi amacı ile sınıflandırma a gooritmaları ile yorumlanmış ve sınıflandırılmıştır. Kahve örneklerinin ölçümleri daha hassas sonuçlar alabilmek için tasarlanan hazne içerisinde gerçekleştirilmiştir.

Yürütülen çalışmada materyalolarak önemlibir içecek olan kahve tercih edilmiştir. Daha ka liteli ve pahalı olan Arabika ve ona göre daha ucuz ve düşük ka liteye sahip olan Robusta türü kahve kullanılmıştır. Kahveler orta kavrulmuş olarak temin edilmiştir. Robusta olarak \% 100 Hindistan Cherry temin edilmiştir. Arabika kahvesi ise Brezilya Rio Minas, Colombia, Guatemala, Kenya, Fine Cup, Honduras, Kosta Rika, Etiyopya orijinli çiğ çekirdeklerin karışımı kullanılmıştır.

Sensörlerden elde edilen sinyaller sinıflandırma a lgoritmaları kullanılarak işlenmiştir. Bu amaçla, SVM (Destek Vektör Makineleri), k-En Yakın Komşu Algoritması, Karar a ğaçları, Naïve Bayes Algoritması ve Doğrusal Ayırma Analizi (LDA) uygulanmıştır.

\subsection{SVM (Destek vektör makineleri)}

Destek Vektör Makineleri, ilk uygulamalarda iki sınıfın ayrılma sında kullanılmasına ra ğmen, za manla geliştirilerek çok sınıflı verilerin yorumlanmasında kullanılır hale gelmiştir (Cortes ve Vapnik, 2009) (Cortes ve Vapnik, 2009).

\section{2. k-En yakın komşu algoritması}

Numunenin sınıfını en yakın komşuya göre analiz eden T. M. Cover ve P. E. Hart tarafından geliştirilen, kullanımı ve öğrenmesi nispeten kolay olan bir sinıflandırma a lgoritmasıdır(Cover ve Hart, 1967).

\subsection{Karar ağaçları}

Karar ağaçları yaprak, dal ve dügüm olmak üzere üç k1sımdan meydana gelen, basit ve anlaş1lır bir a lgoritmadır. Kökü temsil eden düğüm en tepede bulunmaktadır. Dallar orta kısımdadır ve kök ve yapraklar arasında ki bağıntıyı kurmaktadır (Safa vian ve Landgrebe, 1991-Quinlan, 1993).

\subsection{Naïve bayes algoritması}

Girdilerin sınıfını olasılık temeline göre belirleyen matematikçi Thomas Bayes'in ismini alan sınıflandırma algoritmasıdır.

\subsection{Doğrusal ayırma analizi (LDA)}

R. A. Fischer tarafından 1936'da sözü geçen, bir boyut indirgeme analizi olan LDA verilerin sinıfinın belirlenmesini sağlamaktadır (Martinez ve Kak, 2001).

\section{BULGULAR VE TARTIŞMA}

Elektronik burun düzeneği tasarlanırken özdeş sensörler kullanılarak iki ayrı sensör haznesi elde edilmiştir. Bu özdeşlik bize ölçüm sonuçlarının paralelini aynı anda aynı ortam şartlarında ölçebilme olanağı sunmuştur. Özdeş sensörler ile ölçümler gerçekleştirilirken her bir sensör için referans gaz ölçümü yapılıp örnekler ile elde edilen sinyallerden çıkarılmıştır ve ölçüm sonuçlarının aritmetik orta la ma ları a lınmıştır. Böylelikle ortam havası sıfırla narak doğabilecek yanlışlar sıfırlanmıştır. 4'er g kahve örneği üzerine yaklaşık 10 katı kaynar su ilave edilerek 20 dakika boyunca ölçümler gerçekleştirilmiştir. Her bir sensör için \% Arabika ve Robusta kahvelerinin verileri elde edilmiş ve MATLAB programında grafikleri elde edilmiştir. Aşa ğıda ilgili örneklerin sensör gra fikleri verilmiştir. Şekil 2, 3, 4, 5, 6, 7 ve 8'de MQ135, MQ2, MQ3, MQ5, MQ6, MQ7 ve MQ8 sensör sonuçları verilmiştir.
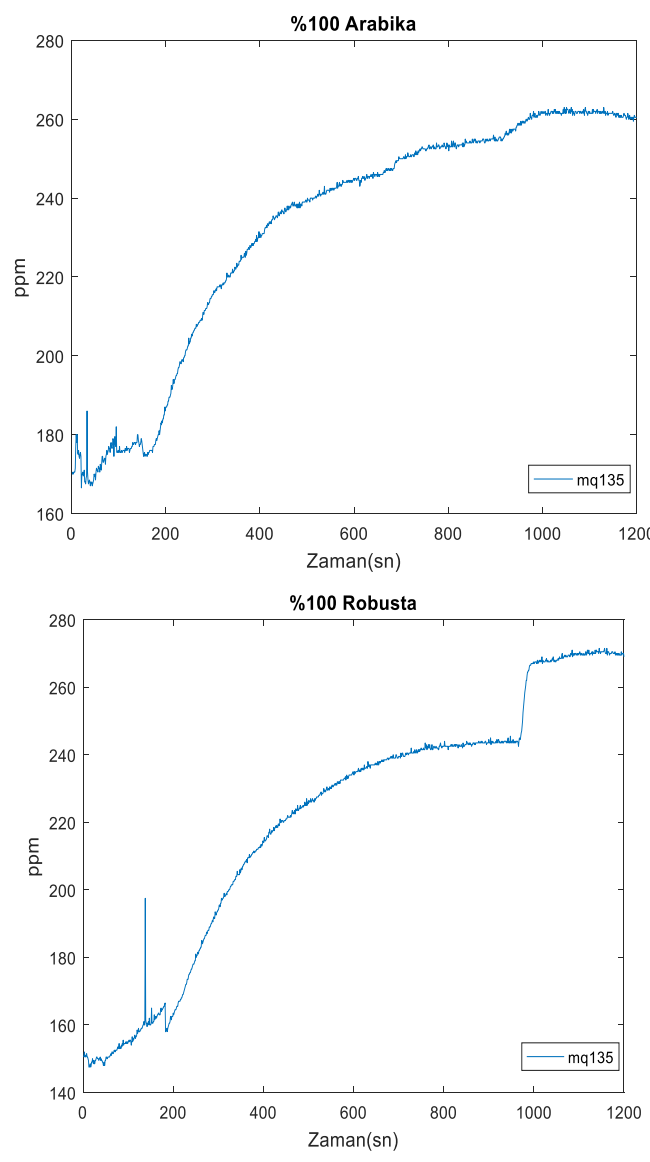

Şekil 2. MQ135 Sensör Sonuçları 

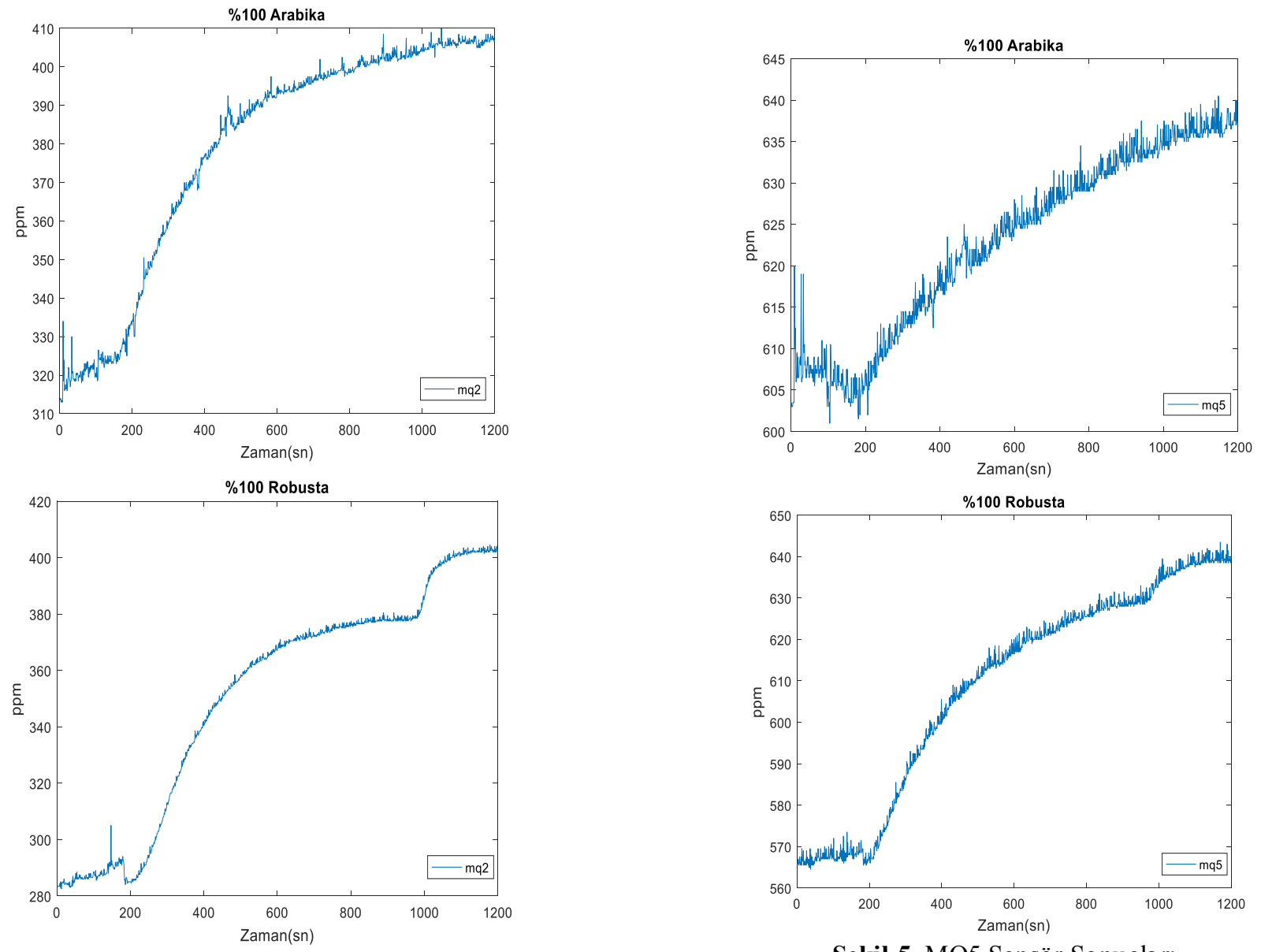

Şekil 3. MQ2 Sensör Sonuçları

Şekil 5. MQ5 Sensör Sonuçları
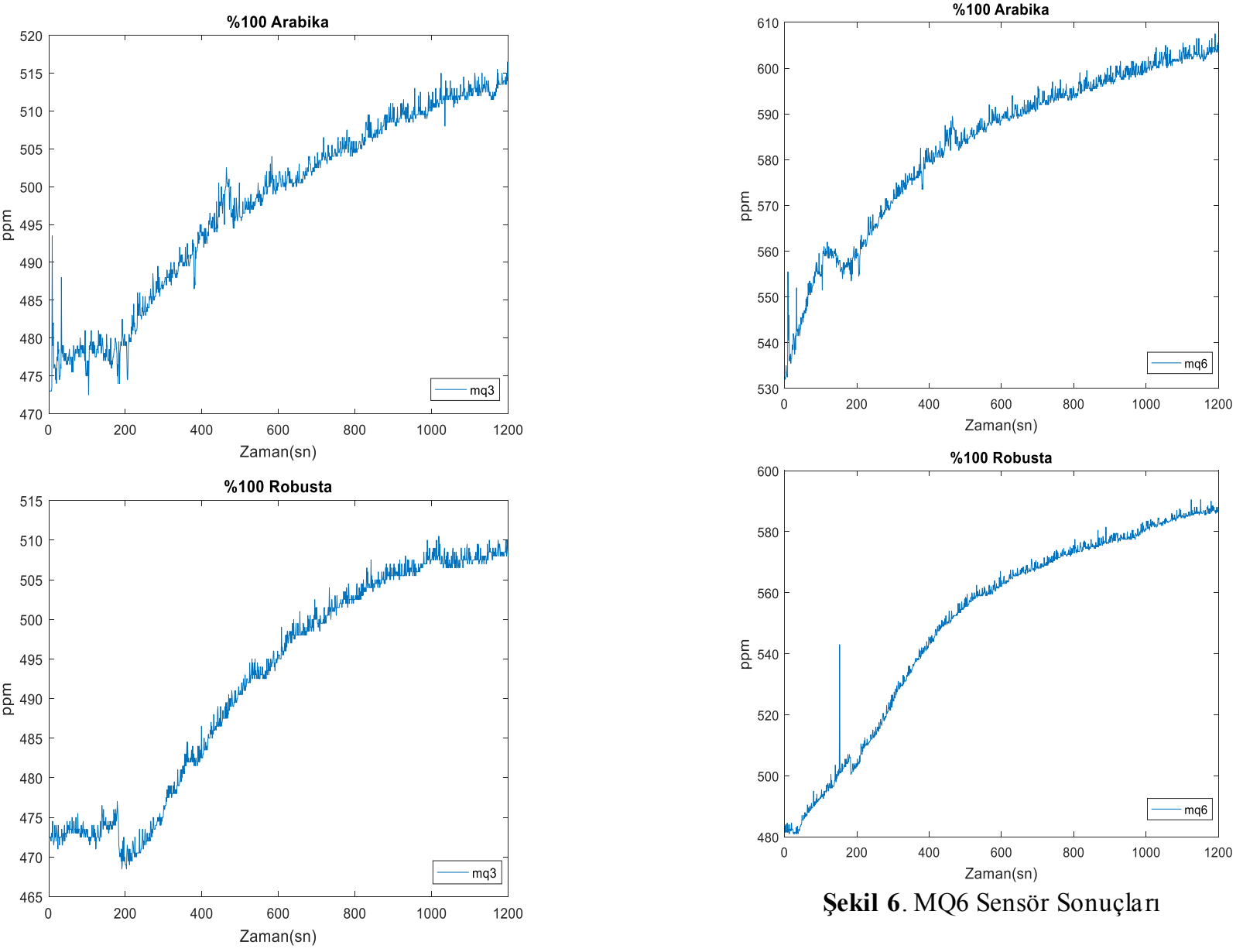

Şekil 6. MQ6 Sensör Sonuçları

Şekil 4. MQ3 Sensör Sonuçları 

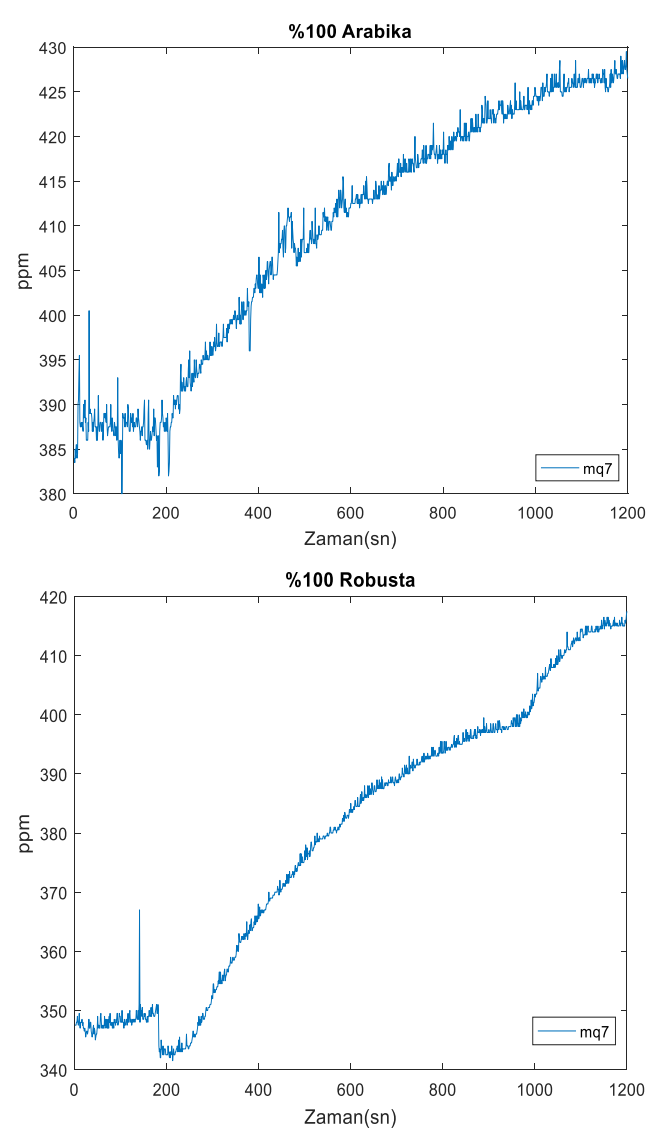

Şekil 7. MQ7 Sensör Sonuçları
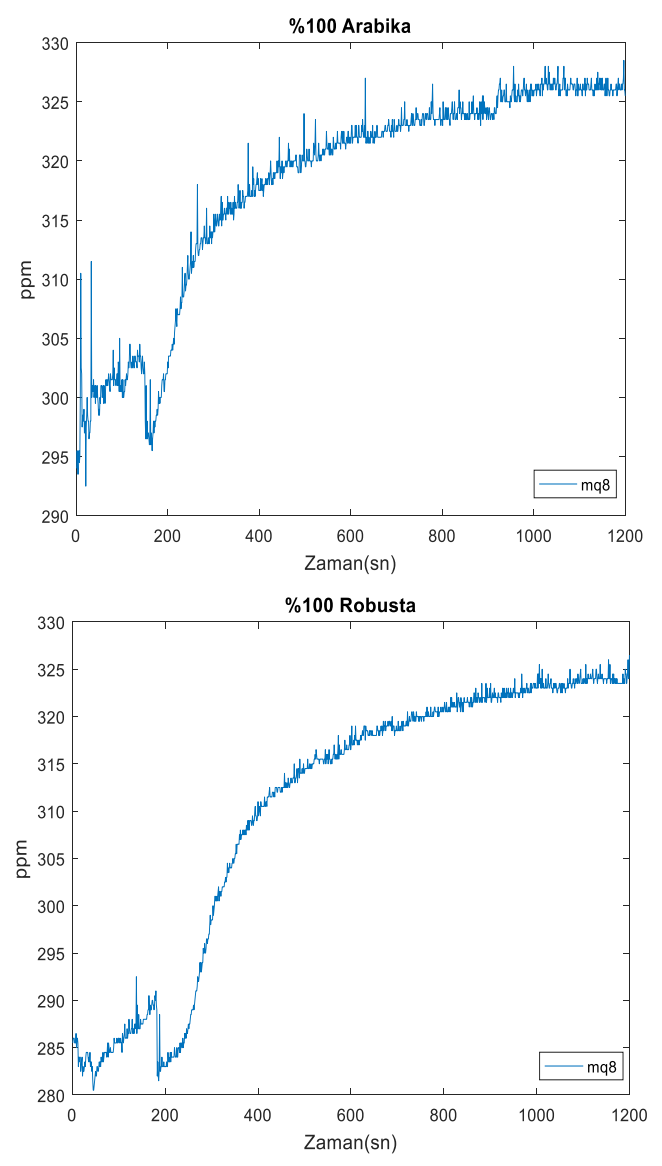

Şekil 8. MQ8 Sensör Sonuçları
$\% 100$ Arabika ve \% 100 Robusta kahve numunelerinin sensör sinyalleri alınmıştır ve yüzde olarak sınıflandırma başarıları analiz edilmiştir. İlgili sonuçlar Tablo 2'de verilmiştir.

Tablo 2. \% 100 Arabika Ve \% 100 Robusta Kahvelerinin Sensör Sonuçlarının Çeşitli Algoritmalara Göre Yüzdesel Sinıflandirilması

\begin{tabular}{|c|c|c|c|c|c|c|c|}
\hline $\begin{array}{l}\text { Sinıflandı } \\
\text { rma } \\
\text { yöntemi }\end{array}$ & $\begin{array}{l}\mathbf{M} \\
\text { Q2 }\end{array}$ & $\begin{array}{l}\mathbf{M} \\
\text { Q3 }\end{array}$ & $\begin{array}{l}\text { M } \\
\text { Q5 }\end{array}$ & $\begin{array}{l}\text { M } \\
\text { Q6 }\end{array}$ & $\begin{array}{l}\mathbf{M} \\
\text { Q7 }\end{array}$ & $\begin{array}{l}\text { M } \\
\text { Q8 }\end{array}$ & $\begin{array}{l}\text { MQ1 } \\
35\end{array}$ \\
\hline Bayes & $\begin{array}{l}58 . \\
50\end{array}$ & $\begin{array}{l}55 . \\
46\end{array}$ & $\begin{array}{l}60 . \\
71\end{array}$ & $\begin{array}{l}65 . \\
17\end{array}$ & $\begin{array}{l}71 . \\
50\end{array}$ & $\begin{array}{l}56 . \\
29\end{array}$ & 53.83 \\
\hline kNN-3 & $\begin{array}{l}77 . \\
38\end{array}$ & $\begin{array}{l}70 . \\
71\end{array}$ & $\begin{array}{l}70 . \\
00\end{array}$ & $\begin{array}{l}75 . \\
79\end{array}$ & $\begin{array}{l}79 . \\
29\end{array}$ & $\begin{array}{l}66 . \\
04\end{array}$ & 78.42 \\
\hline kNN-5 & $\begin{array}{l}77 . \\
42\end{array}$ & $\begin{array}{l}70 . \\
71\end{array}$ & $\begin{array}{l}70 . \\
04\end{array}$ & $\begin{array}{l}75 . \\
88\end{array}$ & $\begin{array}{l}79 . \\
46\end{array}$ & $\begin{array}{l}66 . \\
08\end{array}$ & 78.54 \\
\hline kNN-7 & $\begin{array}{l}77 . \\
21\end{array}$ & $\begin{array}{l}70 . \\
67\end{array}$ & $\begin{array}{l}70 . \\
04\end{array}$ & $\begin{array}{l}76 . \\
00\end{array}$ & $\begin{array}{l}79 . \\
71\end{array}$ & $\begin{array}{l}66 . \\
08\end{array}$ & 78.96 \\
\hline kNN-9 & $\begin{array}{l}77 . \\
42\end{array}$ & $\begin{array}{l}70 . \\
58\end{array}$ & $\begin{array}{l}70 . \\
04\end{array}$ & $\begin{array}{l}76 . \\
75\end{array}$ & $\begin{array}{l}79 . \\
71\end{array}$ & $\begin{array}{l}66 . \\
08\end{array}$ & 79.17 \\
\hline $\begin{array}{l}\text { Karar } \\
\text { ağacı }\end{array}$ & $\begin{array}{l}78 . \\
46\end{array}$ & $\begin{array}{l}69 . \\
21\end{array}$ & $\begin{array}{l}71 . \\
00\end{array}$ & $\begin{array}{l}77 . \\
08\end{array}$ & $\begin{array}{l}80 . \\
92\end{array}$ & $\begin{array}{l}67 . \\
33\end{array}$ & 79.63 \\
\hline OneR & $\begin{array}{l}77 . \\
25\end{array}$ & $\begin{array}{l}70 . \\
54\end{array}$ & $\begin{array}{l}70 . \\
04\end{array}$ & $\begin{array}{l}76 . \\
50\end{array}$ & $\begin{array}{l}79 . \\
75\end{array}$ & $\begin{array}{l}66 . \\
21\end{array}$ & 79.04 \\
\hline SVM & $\begin{array}{l}58 . \\
33\end{array}$ & $\begin{array}{l}55 . \\
67\end{array}$ & $\begin{array}{l}65 . \\
88\end{array}$ & $\begin{array}{l}68 . \\
75\end{array}$ & $\begin{array}{l}73 . \\
08\end{array}$ & $\begin{array}{l}55 . \\
92\end{array}$ & 53.67 \\
\hline LDA & $\begin{array}{l}59 . \\
92\end{array}$ & $\begin{array}{l}56 . \\
58\end{array}$ & $\begin{array}{l}58 . \\
75\end{array}$ & $\begin{array}{l}66 . \\
79\end{array}$ & $\begin{array}{l}72 . \\
42\end{array}$ & $\begin{array}{l}58 . \\
13\end{array}$ & 55.83 \\
\hline
\end{tabular}

Yapılan sınıflandırma çalışmaları neticesinde maksimum yüzdeler Karar a ğaçlarından (decision trees) alınmış olup diğer sınıflandırma yöntemlerine göre daha yüksek başarı sağlamıştır. Arabika ve Robusta ikili ayrımında en iyi sınıflandırma cevabı 80.92 yüzdesi ile MQ7 sensöründen elde edilmiştir.

En iyi sınıflandırma başarısına sahip MQ7 sensöründen elde edilen verilerin karar ăgacı analizi sonucu elde edilen görüntüsü Şekil 9'da görüldügü gibidir.

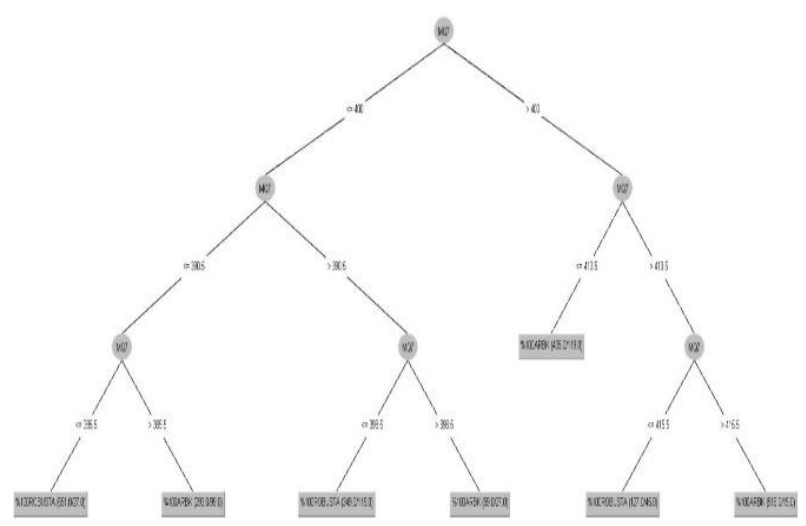

Şekil 9. MQ7 Sensörünün Karar Ağacı Görüntüsü 


\section{TARTIŞMA VE SONUÇLAR}

Kahve sektörü dünya genelinde göze çarpan ve önem arz eden bir alandır. Ticareti çok yapılan bir gıda grubu olduğu için her gida örneğinde olduğu gibi kahvede de eşitli hilelere başvurulmaktadır. Daha ucuz olan kahvelerin kaliteli olanlara ilavesi veya çeşitli tahıl unlarının kahveye karıştırılması bu hilelerden bazılarıdır. $\mathrm{Bu}$ çalışmanın temelini de kahvede gerçekleştirilen daha ucuz kahve örneklerinin maliyeti yüksek olanla ra ilavesi oluşturmuştur. $\mathrm{Bu}$ amaç için elektronik burun düzeneği tasarlanarak Arabika ve Robusta kahvelerinin ayrıştırılması a maçlanmış ve çeşitli sınıflandırma algoritmaları ile sonuçlar elde edilerek, kahvelerin elektronik burun ile \% 80 oranlarında ayrıştırılabildiği sonucuna varılmıştır.

Sensörlerden en iyi ayırmay1 MQ2, MQ7, ve MQ135 sensörlerinin gerçekleştirdiği belirlenmiştir. MQ2 hedef gaz kitlesi Metan-Bütan, MQ7 ve MQ135'in ise alkol buharı olduğu bilinmektedir. Sensörler kahvede bulunan yoğunluklu alkol içeriği dolayısıyla ayrım ya pabilmişlerdir. Elde edilen sinyaller çok fazla olduğu için anlamlı hale getirebilmek için farklı sınıflandırma algoritmaları kullanılmış ve en iyi ayrımın alkole duyarlı MQ7 ve MQ135 sensör cevaplarından karar ağacı ile elde edildiği görülmüştür.

Gerçekleştirilen bu çalışma ile kahvede gerçekleştirilen bir hile hızlı ve ekonomik bir şekilde tespit edilmiştir. Tasarlanan elektronik burun düzeneklerinin en kilit noktası kullanılan sensörlerdir. Sensörlerin hassasiyet aralığına göre daha kaliteli ayrımlar yapılabilmektedir. İlerleyen çalışmalarda et teknolojisi, süt teknolojisi, meyve sebze teknolojisi gibi gıda veya sağlı, ev güvenliği gibi farklı alanlarda daha portatif bir cihaz tasarlanarak çeşitli a raştırma lar gerçekleştirilebilir.

\section{Teşekkür}

$\mathrm{Bu}$ çalışmanın yürütülmesinde Gıda alanında ki yardımlarından dolayı Prof. Dr. Gülcan ÖZKAN ve Öğr. Gör. Yasemin İNCEGÜL'e teşekkürlerimi sunuyorum.

\section{KAYNAKLAR}

Chiu, S. W., Tang, K. T. (2013). Towards a chemiresistive sensor-integrated electronic nose: A review. In Sensors 13(10), 14214-47.

Cortes, C., Vapnik, V. (2009). Support-vector networks. ChemicalBiology \& Drug Design. 297(3), 273-297.

Cover, T. M., Hart, P. E. (1967). Nearest Neighbor Pattern Classification. IEEE Transactions on Information Theory, 13(1), 21-27.

Dey, A. (2018). Semiconductor metal oxide gas sensors: A review. Materials Science and Engineering B, 206217.

Eranna, G., Joshi, B. C., Runthala, D. P., Gupta, R. P. (2004). Oxide materials for development of integrated gas sensors-A comprehensive review.
Critical Reviews in Solid State and Materials Sciences, 29(3-4), 111-188.

M. N., C., Willson, K. C. (1985). Coffee: Botany, Biochemistry and Production of Beans and Beverage. Clifford, M. N. (Ed.)

Martinez, A. M., Kak, A. C. (2001). PCA versus LDA. IEEE Transactions on Pattern Analysis and Machine Intelligence, 23(2), 228-233.

Safavian, S. R., Landgrebe, D. (1991). A Survey of Decision Tree Classifier Methodology. IEEE Transactions on Systems, Man and Cybernetics, 21(3), 660-674.

Salzberg, S. L. (1993). C4.5: Programs for Machine Learning by J. Ross Quinlan. Morgan Kaufmann. 235-240.

Taştan, Y. K. (2009). Sufi Şarabından Kapitalist Metaya Kahvenin Öyküsü. Akademik Bakış, 2(4), 53-86.

Wilkens, F. W., Hartman, J. D. (1964). Wilkens \& Hartman: Electronic Analog. Journal of Food Science, 29(3), 608-612. 